\title{
Short Communication: Rearrangement of Rumenic Acid in Ruminant Fats: A Marker of Thermal Treatment
}

\author{
F. Destaillats, ${ }^{1, *}$ C. Japiot, ${ }^{1}$ P. Y. Chouinard, ${ }^{2}$ J. Arul, ${ }^{1}$ and P. Angers ${ }^{1}$ \\ ${ }^{1}$ Department of Food Science and Nutrition, and Dairy Research Center (STELA), and \\ ${ }^{2}$ Department of Animal Science and STELA, Université Laval, Sainte-Foy, Québec, Canada, G1K 7P4
}

\begin{abstract}
Rumenic (cis-9,trans-11 18:2) acid is the main conjugated linoleic acid (CLA) isomer in milk and other ruminant fats. Anhydrous regular and high-CLA butterfats were heated at $200^{\circ} \mathrm{C}$ for 2,4 , and $6 \mathrm{~h}$ under atmospheric conditions. [1,5] Sigmatropic isomerization of rumenic acid occurred, resulting in the formation of trans-8, cis10 18:2 acid, as determined by mass spectrometry of its 4,4-dimethyloxazoline derivative. Rate of isomerization was monitored by gas-liquid chromatography, using a 120-m capillary column coated with $70 \%$ equivalent cyanoalkylpolysiloxane polymer, and reaction was of first order. Furthermore, [1,5] sigmatropic rearrangement product analysis can be used as an indicator of heat treatment of natural fats and oils containing CLA.

(Key words: conjugated linoleic acid, butterfat, rumenic acid, thermal reaction)
\end{abstract}

Abbreviation key: CLA = conjugated linoleic acids, DMOX = 4,4-dimethyloxazoline derivative, $\mathbf{F A}=$ fatty acids, FAME = fatty acid methyl ester.

Conjugated linoleic acids (CLA) represent a mixture of conjugated octadecadienoic acid isomers. Their formation from linoleic acid depends upon their origin—natural or synthetic. In animal products such as milk fat and beef tallow, their occurrence is related to incomplete biohydrogenation of polyunsaturated fatty acids in the rumen (Kepler et al., 1966). In these products, rumenic (cis9,trans-11 18:2) acid represents about 80 to $90 \%$ of total CLA isomers; minor geometrical and positional isomers ranging from $\Delta^{7,9}$ to $\Delta^{12,14}$ are also present (Turini and Martin, 2001). Another route leading to the formation of rumenic acid is by in vivo $\Delta^{9}$-desaturation of vaccenic (trans-11 18:1) acid (Griinari et al., 2000).

Conjugated linoleic acids mixtures for use in clinical studies or for analytical purposes are usually synthesized

Received November 8, 2004.

Accepted January 21, 2005.

Corresponding author: Paul Angers; e-mail: paul.angers@fsaa. ulaval.ca.

*Present address: Nestlé Research Center, Vers-chez-les-Blanc, Lausanne, Switzerland. by alkali isomerization of linoleic (cis-9,cis-12 18:2) acid, and consist mainly of cis-9,trans-11 18:2, and trans10,cis-12 18:2 acids. In addition, the process may result in the formation of significant amounts of trans-8,cis10 18:2 and cis-11,trans-13 18:2 acids as well as minor concentrations of all cis- and all trans-8,10 18:2, 9,11 18:2, 10,12 18:2, and 11,13 18:2 acids (Eulitz et al., 1999; Juaneda et al., 2001; Destaillats and Angers, 2003).

The role of specific isomers in various biological activities observed with commercial supplements of CLA has been reviewed by Pariza et al. (2001). In particular, rumenic acid has been shown to possess anticarcinogenic activity. This isomer was found effective in animal models for breast cancer when consumed as a natural component of foods including a dietary supplement of butterfat enriched in rumenic acid by cow feeding (Ip et al., 1999).

We have shown earlier that rumenic and trans-10,cis12 18:2 acids thermally isomerize through a [1,5] sigmatropic or pericyclic reaction mechanism into trans-8,cis10 18:2, and cis-11,trans-13 18:2 acids, respectively (Destaillats and Angers, 2002). This reaction, widely exploited in organic synthesis, was reviewed by Spangler (1976). The specificity of this reaction is due to both orbital symmetry, and structural geometry of the conjugated double bond system under pericyclic rearrangement. Combined with Se-catalyzed isomerization, [1,5] sigmatropic reaction resulted in a simple synthesis of CLA isomers, for use in chromatographic identification such as for milk fat, as well as for preparation of CLA standard mixtures (Destaillats and Angers, 2003).

We report on the formation of trans-8,cis-10 18:2 acid from rumenic acid in anhydrous regular and high-CLA butterfats, under thermal conditions that are encountered in food processing, and in refined beef tallow.

\section{Reference Compounds and Reagents}

Fatty acid methyl ester (FAME) standard of cis9,trans-11 18:2 was purchased from Nu-Chek Prep (Elysian, MN). 2-Amino-2-methyl-1-propanol was obtained from Aldrich Chemicals (Milwaukee, WI).

\section{Bovine Milk Fat}

The regular winter milk fat was a sample from Parmalat (Montréal, Québec, Canada). A 25-kg block was 
tempered and then divided into 100-g samples, which were rapidly melted, washed with deionized water, dried over anhydrous sodium sulfate, filtered at $60^{\circ} \mathrm{C}$ in a forced-air oven, and kept under $\mathrm{N}_{2}$ in closed vials at $-35^{\circ} \mathrm{C}$ until utilization. For the preparation of high CLA butter, 30 cows were fed a diet supplemented with sunflower oil at 5\% of DM according to Bauman et al. (2000). Milk samples were taken after $3 \mathrm{wk}$ on this diet to determine the CLA concentration. Cows with the greatest concentration of CLA continued on the diet for milk collection and butter manufacturing. Anhydrous milk fat was obtained from high-CLA butter as described for regular butter.

\section{Beef Tallow}

Raw beef tallow was kindly provided by a local grocery store (Québec, Canada), and was extracted according to Folch (Folch et al., 1957). Samples were dried over anhydrous sodium sulfate, filtered, and kept at $-20^{\circ} \mathrm{C}$ under $\mathrm{N}_{2}$ until analysis. Refined beef tallow was a gift of Canamera Foods (Montréal, Québec, Canada).

\section{Thermal Treatment}

Butterfat samples $(500 \mu \mathrm{L})$ were heated under air in sealed glass vials for 2,4 , and $6 \mathrm{~h}$ at $200^{\circ} \mathrm{C}$ in the oven of a 5890A gas chromatograph (Hewlett-Packard, Palo Alto, CA). Butterfat samples were collected after heat treatment, and methylated using sodium methoxide in methanol as catalyst before gas chromatography analyses. All experiments were performed in duplicate.

\section{FAME Analysis}

Analysis of FAME was performed on a 6890 Series II gas chromatograph (Hewlett-Packard), equipped with a 120-m fused silica, BPX-70 capillary column made by connecting 2 capillary columns (equivalent to $70 \%$ cyanoalkylpolysiloxane; $60 \mathrm{~m} \times 0.25 \mathrm{~mm}$ i.d., $250 \mu \mathrm{m}$ film thickness; SGE, Melbourne, Australia) using a universal press-tight connector (Restek, Brockville, CA). The apparatus was connected to a ChemStation (Hewlett-Packard), and injection (split mode) and detection (flame ionization detector) were performed at $250^{\circ} \mathrm{C}$. Oven temperature programming was $60^{\circ} \mathrm{C}$ isothermal for $1 \mathrm{~min}$, increased to $170^{\circ} \mathrm{C}$ at $20^{\circ} \mathrm{C} / \mathrm{min}$, and isothermal for 40 $\min$ at $170^{\circ} \mathrm{C}$. The inlet pressure of the carrier gas $\left(\mathrm{H}_{2}\right)$ was $300 \mathrm{kPa}$ at $170^{\circ} \mathrm{C}$. The chromatographic peaks were identified based on previous work (Destaillats and Angers, 2002, 2003) and literature data (Lavillonière et al., 1998; Sehat et al., 1998a,b; Christie et al., 2001; Kramer et al., 2001; Kramer and Zhou, 2001). Under these chromatographic conditions, rumenic FAME over-

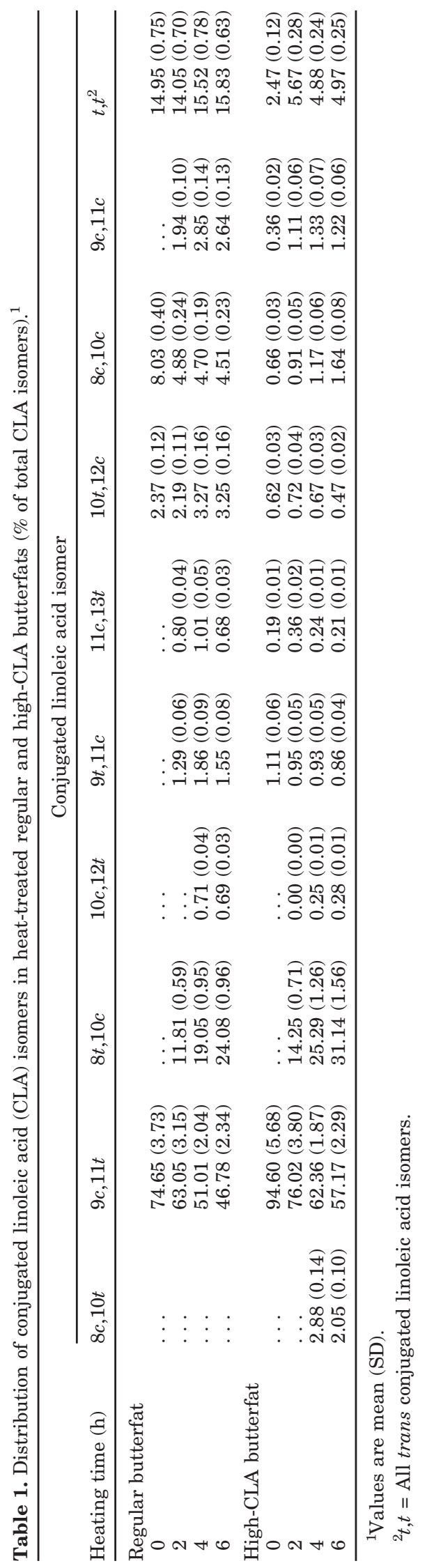


lapped with that of arachidic acid (20:0), thus the corresponding peak area must be corrected to account for the coeluting 20:0 acid. Methyl eicosenoate (cis/trans 20:1) also coeluted with cis-10,cis-12 18:2 and cis-11,cis-13 18:2 acid methyl esters, and therefore, these CLA isomers were not quantified in this work.

\section{Preparation of 4,4-Dimethyloxazoline Derivatives}

4,4-Dimethyloxazoline (DMOX) derivatives of fatty acids (FA) were prepared using a modified literature procedure (Fay and Richli, 1991; Garrido and Medina, 1994) from FAME, using 2-amino-2-methyl-1-propanol $(500 \mu \mathrm{L})$ by heating at $150^{\circ} \mathrm{C}$ overnight under a nitrogen atmosphere. The temperature was accurately controlled to prevent sigmatropic rearrangements of conjugated FA which occur readily at temperatures $>170^{\circ} \mathrm{C}$ (Destaillats and Angers, 2002).

\section{Gas Chromatography-Mass Spectrometry Analysis of DMOX Derivatives}

4,4-Dimethyloxazoline derivatives were analyzed by gas chromatography-mass spectrometry. A gas chromatograph (model 6890 Series II, Hewlett-Packard) was attached to a selective quadrupole mass detector (model 5973N, Agilent Technologies, Palo Alto, CA)] under an ionization voltage of $70 \mathrm{eV}$, and connected to a computer with a Hewlett-Packard ChemStation. The injector, in split mode (25:1), and the interface temperatures were maintained at $230^{\circ} \mathrm{C}$, and $\mathrm{He}$ was used as carrier gas under constant flow rate $(1 \mathrm{~mL} / \mathrm{min})$. Gas-liquid chromatography separation was performed on a BPX-70 capillary column (SGE; $60 \mathrm{~m} \times 0.25 \mathrm{~mm}$ i.d., $0.25 \mu \mathrm{m}$ film thickness) with the following temperature program: isothermal at $60^{\circ} \mathrm{C}$ for $2 \mathrm{~min}$, then increased to $180^{\circ} \mathrm{C}$ at $20^{\circ} \mathrm{C} / \mathrm{min}$, then increased to $200^{\circ} \mathrm{C}$ at $2^{\circ} \mathrm{C} / \mathrm{min}$, and isothermal at this temperature for $20 \mathrm{~min}$.

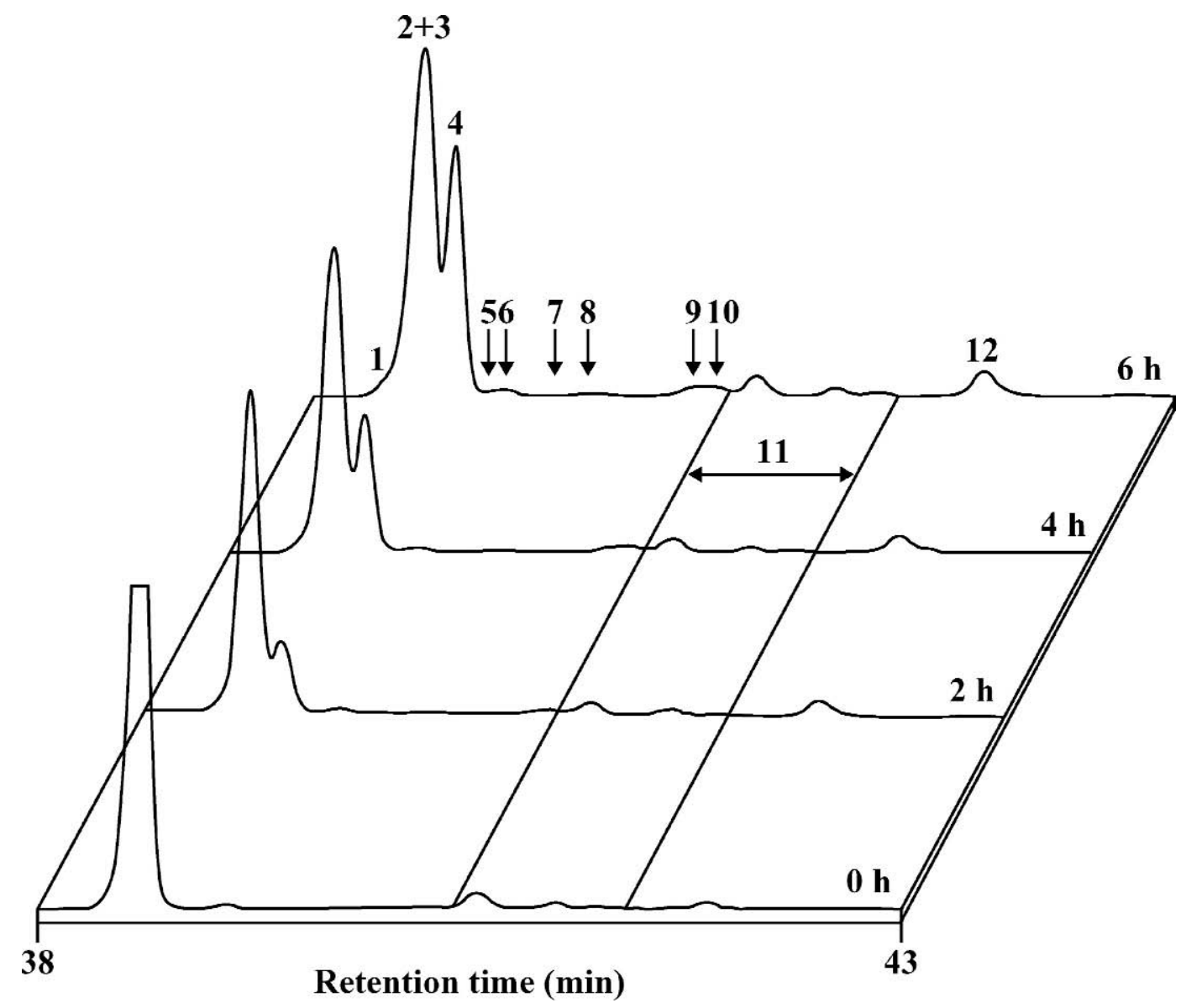

Figure 1. Gas chromatograms of CLA region of heat-treated high-CLA butterfat during heating at $200^{\circ} \mathrm{C}$ for varying periods. Analysis was performed on a 120-m BPX-70 capillary column (see Materials and Methods). Peak identification: $1=$ cis-8,trans-10; $2=\mathrm{C} 20: 0$ (coelution

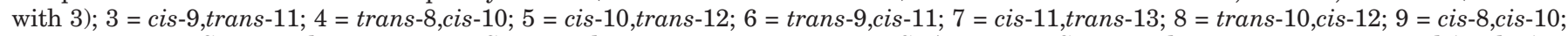
$10=$ cis-9,cis-11 C18:2 acid isomers; $11=$ C20:1 acid isomers; 12 = trans,trans CLA isomers. Compound trans-8,cis-10 18:2 acid (peak 4 ) is the main degradation product formed by thermal rearrangement of cis-9,trans-11 18:2 acid (rumenic acid, peak 3). 


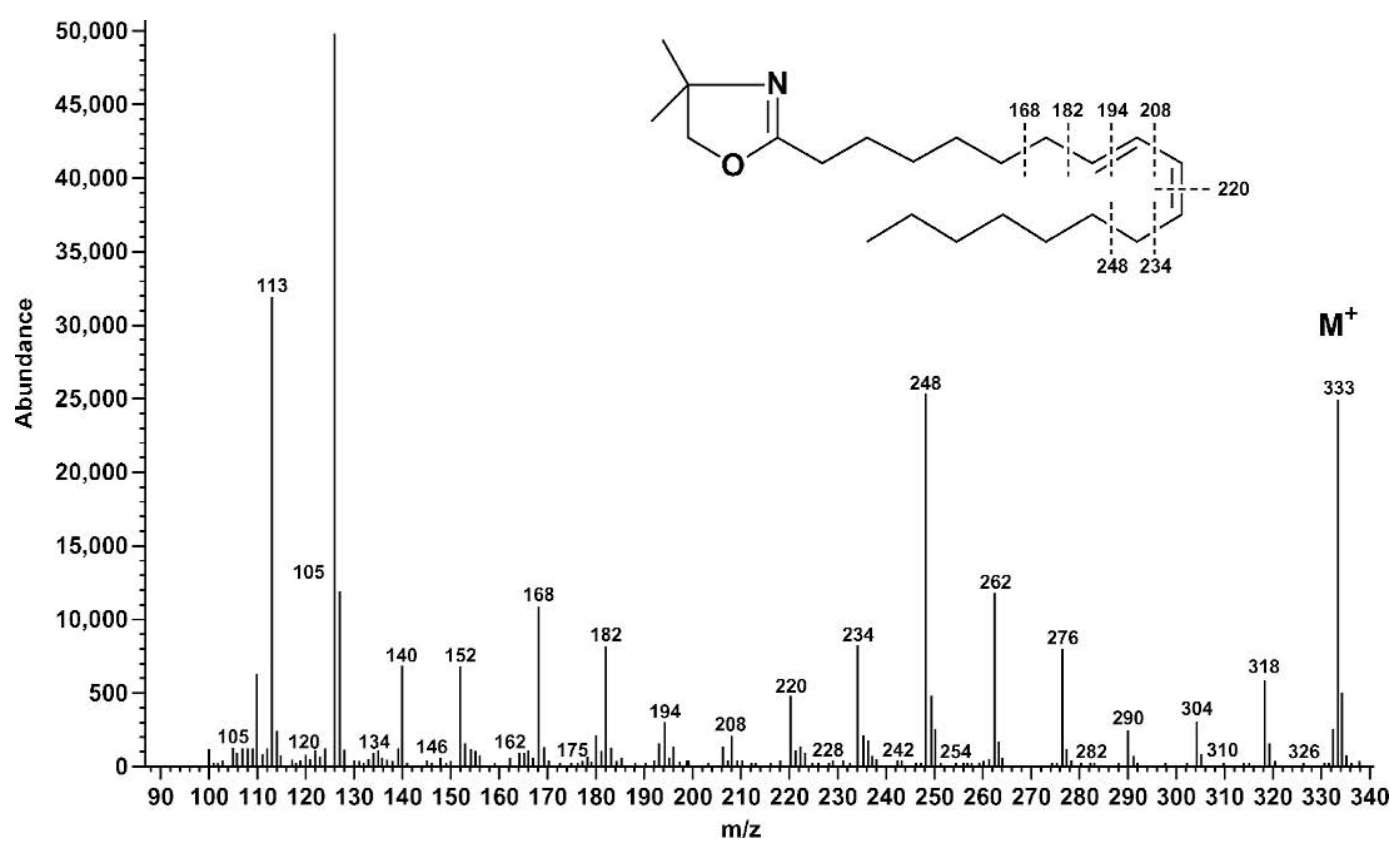

Figure 2. Mass spectrum of the 4,4-dimethyloxazoline (DMOX) derivative of trans-8,cis-10 18:2 acid in heat-treated butterfat.

Regular and high-CLA butterfats were heated for 2, 4 , and $6 \mathrm{~h}$ at $200^{\circ} \mathrm{C}$ under air to simulate conditions that may be encountered in food processing. Fatty acid compositions were determined by gas chromatography using a polar capillary column; the total CLA content remained constant for both samples throughout heat treatment at $200^{\circ} \mathrm{C}$, from 0 to $6 \mathrm{~h}$. However, relative proportions of CLA isomers varied over the heating duration (Table 1), and the effect of thermal exposure on CLA distribution was significant. The rearrangement of rumenic acid into trans-8,cis-10 18:2 FA in butterfat was detectable after $2 \mathrm{~h}$ of heating (Figure 1), and the conversion appears to be of first order, over the time studied.

These results suggest that CLA composition can be used to indicate heat-treated natural fats and oils containing CLA. This was confirmed by comparative analysis of native and refined beef tallow for their CLA composition. The results showed that the main CLA isomer in native beef tallow was rumenic acid. However, as observed for heat-treated butter fats, refined beef tallow also contained trans-8,cis-10 18:2 acid as a major CLA isomer. This acid was not detected in the native fat (results not shown). Moreover, the chromatograms in Figure 1 show the presence of products resulting from similar [1,5] sigmatropic rearrangements of trans-9,cis-11 18:2 and trans-10, cis-12 18:2 acids into cis-10,trans-12 18:2 and cis-11,trans-13 18:2 acids, respectively.

The structure of the major CLA isomer formed on heating/refining was confirmed by gas chromatography-mass spectroscopy analysis of its DMOX derivative using elec- tron impact ionization at $70 \mathrm{eV}$ (Figure 2). The molecular ion at $\mathrm{m} / \mathrm{z}=333$ is indicative of an 18:2 FA. Location of double bonds is indicated by 2 gaps of $12 \mathrm{amu}$ at $\mathrm{m} / \mathrm{z}=$ 220 for the $\Delta^{10}$ double bond, and $\mathrm{m} / \mathrm{z}=194$ for the $\Delta^{8}$ double bond (Fay and Richli, 1991). They represent cleavages between $\mathrm{C} 10$ and $\mathrm{C} 11$, and between $\mathrm{C} 8$ and $\mathrm{C} 9$, respectively. The occurrence of 2 prominent allylic ion fragments at $\mathrm{m} / \mathrm{z}=168$ and 248 , and of 3 vinylic ion fragments at $\mathrm{m} / \mathrm{z}=182,208$, and 234 further confirms the location of the conjugated system. The configuration of double bonds was imposed by the [1,5] sigmatropic rearrangement (Figure 3). Minor cis/trans, cis/cis, and trans / trans CLA isomers were also formed from rumenic and trans-8,cis-10 18:2 acids by a combination of geometrical isomerization and $[1,5]$ sigmatropic rearrangements (Destaillats and Angers, 2005).

This study shows that rumenic acid, the main CLA isomer naturally found in milk fat, rearranges into trans8,cis-10 18:2 FA upon heat treatment of regular and highCLA butterfats. Such conditions may be encountered in food processing, such as refining of fats and oils, which can lead to destruction of rumenic acid, a bioactive isomer of CLA. Furthermore, the thermal rearrangement described here can be used as an indicator of heat treatment of natural fats and oils containing CLA. This finding is important to understand how to prevent the degradation of this bioactive molecule by industrial processing.

\section{ACKNOWLEDGMENTS}

We acknowledge financial support of the Dairy Farmers of Canada and of Natural Sciences and Engineering 
<smiles>[R2]C/C=C\C=C/C([R2])C[R]</smiles>

cis-9, trans-11 18:2

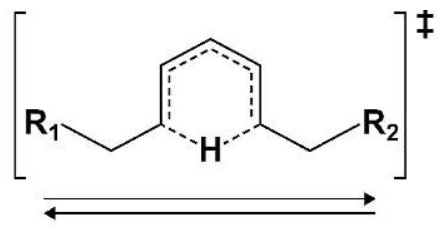

$\Delta$<smiles>[R2]C/C=C\C=C/CC[R2]</smiles>

trans-8, cis-10 18:2

$$
\begin{aligned}
& \mathrm{R}_{\mathbf{1}}=\left(\mathrm{CH}_{2}\right)_{5} \mathrm{COOH} \\
& \mathrm{R}_{\mathbf{2}}=\mathrm{C}_{5} \mathrm{H}_{11}
\end{aligned}
$$

Figure 3. [1,5] Sigmatropic rearrangement of rumenic (cis-9,trans-11 18:2) acid into trans-8,cis-10 18:2 acid.

Council of Canada. The authors are also grateful to Fondation de l'Université Laval (Quebec, Canada) for a Ph.D. scholarship to F. Destaillats.

\section{REFERENCES}

Bauman, D. E., D. M. Barbano, D. A. Dwyer, and J. M. Griinari. 2000. Production of butter with enhanced conjugated linoleic acid for use in biomedical studies with animal models. J. Dairy. Sci. 83:2422-2425.

Christie, W. W., J. L. Sébédio, and P. Juanéda. 2001. A practical guide to the analysis of conjugated linoleic acid (CLA). Inform 12:147-152.

Destaillats, F., and P. Angers. 2002. Evidence for a [1,5] sigmatropic rearrangement in conjugated linoleic acids in heated oils. Lipids 37:435-438.

Destaillats, F., and P. Angers. 2003. Directed sequential synthesis of conjugated linoleic acid isomers from $\Delta^{7,9}$ to $\Delta^{12,14}$. Eur. J. Lipid Sci. Technol. 105:3-8.

Destaillats, F., and P. Angers. 2005. Thermally induced formation of conjugated isomers of linoleic acid. Eur. J. Lipid Sci. Technol. 107:167-172.

Eulitz, K., M. P. Yurawecz, N. Sehat, J. Fritsche, J. A. G. Roach, M. M. Mossoba, J. K. G. Kramer, R. O. Adlof, and Y. Ku. 1999. Preparation, separation, and confirmation of the eight geometrical cis / trans conjugated linoleic acid isomers 8,10 through 11,13-18:2. Lipids 34:873-877.

Fay, L., and U. Richli. 1991. Location of double bonds in polyunsaturated fatty acids by gas chromatography-mass spectrometry after 4,4-dimethyloxazoline derivatization. J. Chromatogr. 541:89-98.

Folch, J., M. Lees, and G. H. Sloane-Stanley. 1957. A simple method for the isolation and purification of total lipids from animal tissues. J. Biol. Chem. 226:497-509.

Garrido, J. L., and I. Medina. 1994. One-step conversion of fatty acids into their 2-alkenyl-4,4-dimethyloxazoline derivatives directly from total lipids. J. Chromatogr. 673:101-105.

Griinari, J. M., B. A. Corl, S. H. Lacy, P. Y. Chouinard, K. V. V. Nurmela and D. E. Bauman. 2000. Conjugated linoleic acid is synthesized endogenously in lactating dairy cows by delta-9 desaturase. J. Nutr. 130:2285-2291.

Ip, C., S. Banni, E. Angioni, G. Carta, J. McGinley, H. J. Thompson, D. Barbano, and D. E. Bauman. 1999. Conjugated linoleic acidenriched butterfat alters mammary gland morphogenesis and reduces cancer risk in rats. J. Nutr. 129:2135-2142.

Juaneda, P., O. Cordier, S. Gregoire, and J. L. Sébédio. 2001. Conjugated linoleic acid (CLA) isomers in heat-treated vegetable oils. OCL-Ol. Corps Gras Li. 8:94-97.

Kepler, C. R., K. P. Hirons, J. J. McNeill, and S. B. Tove. 1966. Intermediates and products of the biohydrogenation of linoleic acid by Butyrivibrio fibrisolvens. J. Biol. Chem. 241:1350-1354.

Kramer, J. K. G., C. Cruz-Hernandez, and J. Zhou. 2001. Conjugated linoleic acids and octadecenoic acids: Analysis by GC. Eur. J. Lipid Sci. Technol. 103:600-609.

Kramer, J. K. G., and J. Zhou. 2001. Conjugated linoleic acid and octadecenoic acids: extraction and isolation of lipids. Eur. J. Lipid Sci. Technol. 103:594-600.

Lavillonière, F., J. C. Martin, P. Bougnoux, and J. L. Sébédio. 1998. Analysis of conjugated linoleic acid isomers and content in French cheeses. J. Am. Oil Chem. Soc. 75:343-352.

Pariza, M. W., Y. Park, and M. E. Cook. 2001. The biologically active isomers of conjugated linoleic acid. Prog. Lipid Res. 40:283-298.

Sehat, N., J. K. G. Kramer, M. M. Mossoba, M. P. Yurawecz, J. A. G. Roach, K. Eulitz, K. M. Morehouse, and Y. Ku. 1998a. Identification of conjugated linoleic acid isomers in cheese by gas chromatography, silver-ion high liquid chromatography and mass spectral reconstructed ion profiles. Comparison of chromatographic elution sequences. Lipids 33:963-970.

Sehat, N., M. P. Yurawecz, J. A. G. Roach, M. M. Mossoba, J. K. G. Kramer, and Y. Ku. 1998b. Silver-ion high liquid chromatography separation and identification of conjugated linoleic acid isomers. Lipids 33:217-221.

Spangler, C. W. 1976. Thermal $[1, j]$ sigmatropic rearrangements. Chem. Rev. 76:187-217.

Turini, M. E., and J. C. Martin. 2001. Sources, functions, and analysis of conjugated linoleic acid and its metabolites. Pages 251-284 in Structured and Modified Lipids. F. D. Gunstone, ed. Marcel Dekker, New York, NY. 